\title{
Editorial \\ Microporous Zeolites and Related Nanoporous Materials: Synthesis, Characterization and Application in Catalysis
}

\author{
Narendra Kumar
}

check for

updates

Citation: Kumar, N. Microporous Zeolites and Related Nanoporous Materials: Synthesis, Characterization and Application in Catalysis.

Catalysts 2021, 11, 382.

https://doi.org/10.3390/catal 11030382

Received: 5 March 2021

Accepted: 9 March 2021

Published: 16 March 2021

Publisher's Note: MDPI stays neutral with regard to jurisdictional claims in published maps and institutional affiliations.

Copyright: (C) 2021 by the author. Licensee MDPI, Basel, Switzerland. This article is an open access article distributed under the terms and conditions of the Creative Commons Attribution (CC BY) license (https:/ / creativecommons.org/licenses/by/ $4.0 /)$.
Laboratory of Industrial Chemistry and Reaction Engineering, Johan Gadolin Process Chemistry Centre, Faculty of Science and Engineering, Åbo Akademi University, Biskopsgatan 8, FI-20500 Turku/Åbo, Finland; narendra.kumar@abo.fi

Microporous zeolites and related nanoporous materials have been studied intensively in academic and industrial laboratories around the world. The reasons for interest in these materials are the unique properties of microporous zeolites such as uniform channel systems, pore dimensions, shape selectivity, tunable Brønsted and Lewis acidic sites, coke resistance, ion-exchange and thermal stability properties. The primary focus of research in this field has been synthesis, characterization and applications of acidic, noble and transition metal-modified microporous zeolites and related nanoporous materials. It should be mentioned that since the 1960s, these catalytic materials have been utilized in several industrial processes for synthesis of high-quality gasoline, aromatics, isomers and ethyl benzenes. Furthermore, development of novel catalyst synthesis technology and invention of new types of microporous zeolites with varying structures has led to the application of these catalytic materials in petro-chemical productions, oil refinery processes, and speciality and fine chemical syntheses. In recent years, microporous, medium porous and large porous zeolites and related nanoporous materials have been studied for applications in green chemical processes, environmentally friendly technologies, purification of industrial wastewater, exhaust-emission control, synthesis of pharmaceuticals, drugs, medicinal products and carriers for proteins and drug molecules.

The Special Issue of Catalysts contains 12 published papers. One of these published papers is a review article [1] regarding the processes theory for irregular pores; the remaining 11 are research papers [2-12]. The research paper on Zn-Co@N-Doped carbon derived from ZIFs for high-efficiency synthesis of ethyl methyl carbonate and the formation of $\mathrm{ZnO}$ and the interaction between $\mathrm{Co}$ and $\mathrm{Zn}$ [2] elaborates on the synthesis and characterization of the Zn-Co-modified zeolitic imidazolate framework (ZIF) for the synthesis of ethyl methyl carbonate. The significant research results were the synthesis of a new type of zeolite material zeolitic imidazolate framework (ZIF). Furthermore, it was reported that the loading of cobalt and calcination temperature influenced the particle size, oxidation states and catalytic properties.

Synthesis of large pore zeolites is important from the point of view of processing of large size organic compounds. The direct synthesis of Ti-containing CFI-type extra-large pore zeolites in the presence of fluorides was achieved in [3]. The Ti-CFi catalyst was synthesized with addition of seeds to enhance the crystallization process and decrease the crystallite size.

The methanol to olefin process is a very important industrial process for the production of olefins. There is a significant issue with the stability of catalysts due to coke formation. Hence, there is continuous research regarding the development of new catalytic materials. ZSM-5 zeolite embedded in an amorphous silica matrix were highly selective catalysts for propylene in the methanol-to-olefin process [4]. Since the amount, strength and distributions of Brønsted acid sites are important for the production of olefins, embedding of microporous zeolites in amorphous silica gives new direction for synthesis of tailored acid sites. 
Silicalite-1 zeolite modified with chromium oxide has been used for dehydrogenation of isobutane to isobutene in presence of $\mathrm{CO}_{2}$. Isobutene is used for the production of butyl rubber, fuel components such as ethyl-butyl ether and antioxidants such as butylated hydroxyanisole. Chromium oxide is supported on silicalite- 1 zeolite as a novel efficient catalyst for dehydrogenation of isobutene assisted by $\mathrm{CO}_{2}$ in [5]. Oxidative dehydrogenation of light alkanes such as propane, butane and isobutene using $\mathrm{CO}_{2}$ is very cost-effective way to obtain isobutene.

Contamination of river, sea and ocean water with pharmaceutical components is a growing environmental problem which needs immediate solutions through development of advanced technologies. Taking into consideration the limited water resources, development of green processes for purifications of pharmaceutical contaminated water is of immense importance. An advanced oxidation process for degradation of carbamazepine from aqueous solutions using metal modified microporous, mesoporous catalysts is covered in $[6,8,9]$. The research paper reports the metal-modified catalytic materials for removal of pharmaceuticals from the wastewater.

Diclofenac, a nonsteroidal anti-inflammatory drug used for treatment of osteoarthritis, rheumatoid arthritis, migraine headache and menstrual cramps, has been found in fresh water sources. The removal of diclofenac from the water sources is important for the environmental, ecological, wastewater purification and sustainable development of biodiversity. Different types of catalytic materials such as acidic and Pt-modified MCM-22 microporous zeolites and $\mathrm{Pt}-\mathrm{Al} 2 \mathrm{O} 3$ catalysts have been studied for the removal of diclofenac from aqueous solution sources. It was observed that Pt-modified MCM-22 zeolite catalysts enhanced the degradation of diclofenac. A method using Pt-modified heterogeneous catalysts combined with ozonation for the removal of diclofenac from aqueous solutions and fate of by-products can be seen in [8].

Isosorbide is used as an important biomaterial in the pharmaceutical industry. Green process technology development for synthesis of pure isosorbide from sorbitol has been proposed using different types of catalytic materials. The research published in this special issue utilizes Mordenite, ZSM-5, MCM-22, USY and Beta zeolites with varying structures and acidic properties for synthesis of isosorbide from sorbital. Catalytic properties of microporous zeolite catalysts in synthesis of isosorbide from sorbitol by dehydration is covered in [7].

Production of para-xylene using the H-ZSM-5 zeolite catalyst is an important industrial chemical technology in the oil refinery process. There has been continuous research in development of new selective catalysts for synthesis of para-xylene. Selective synthesis of para-xylene over P-ZSM-5 zeolite catalysts by methanol aromatization and a method of phosphorus modification of physico-chemical and catalytic properties is described in [10]. The research papers also elaborate on the influence of phosphorus modifications on Brønsted and Lewis acid sites, crystallinity and surface area of P-ZSM-5 zeolite catalysts.

Synthesis, characterization and applications of CHA-type zeolite in several reactions have attracted the attention of academic and industrial research laboratories. In-depth research regarding the preparation of CHA-type zeolites using FAU- and LTL-type zeolites as raw materials and the influence of variations of synthesis parameters, reaction mechanism and catalytic properties has been reported [11]. The synthesized CHA zeolite catalyst showed high catalytic activity and selectivity in conversion of methanol to olefins.

Campholenic aldehyde and trans-carveol are important chemicals used in the synthesis of pharmaceuticals, medicinal products, speciality chemicals, drug molecules and fragrances productions. These chemical compounds are obtained by catalytic isomerization of $\alpha$-pinene oxide using different types of metal-modified heterogeneous catalytic materials. The effect of solvents, metal nanoparticle size distributions, dispersion of $\mathrm{MoO}_{3}$ in Beta zeolite, surface area and structural properties have been studied in $\alpha$-pinene oxide isomerization reactions [12].

The research papers published in the Special Issue "Microporous zeolites and related nanoporous materials: synthesis, characterization and application in catalysis" reflect 
the novel trends in the synthesis of petro-chemicals, fuel components, fine and speciality chemicals, pharmaceuticals, drug molecules and fragrances using principles of sustainable development of our planet, green process technology, environmentally friendly technology and mitigation of climate change. Furthermore, research results in these published papers will enhance and deepen the scientific knowledge of younger generations of academicians, researchers, scientists and engineers working in the field of heterogeneous catalysis, catalyst synthesis and characterization, reaction mechanisms, zeolite synthesis, oil refinery processes, environmental catalysis and porous materials productions.

Institutional Review Board Statement: Not applicable.

Informed Consent Statement: Not applicable.

Conflicts of Interest: The author declares no conflict of interest.

\section{References}

1. Santamaria-Holek, I.; Hernandez, S.I.; Gracia-Alcantara, C.; Ledesma-Duran, A. Review on macro-transport process theory for irregular pores able to perform catalytic reactions. Catalysts 2019, 9, 281. [CrossRef]

2. Miao, Y.; Wang, Y.; Pan, D.-H.; Song, X.-H.; Xu, S.-Q.; Gao, L.-J.; Xiao, G. Zn-Co@N-Doped carbon derived from ZIFs for high efficiency synthesis of ethyl methyl carbonate: The formation of $\mathrm{ZnO}$ and the Interaction between Co and Zn. Catalysts $2019,9,94$. [CrossRef]

3. Wang, Y.; Wang, H.; Shao, Y.; Li, T.; Tatsumi, T.; Wang, J.G. Direct synthesis of Ti-containing CFI-type extra-large-pore zeolites in the presence of fluorides. Catalysts 2019, 9, 257. [CrossRef]

4. Kamaluddin, H.S.; Basahel, S.N.; Narasimharao, K.; Mukhtar, M. H-ZSM-5 materials embedded in an amorphous silica matrix: Highly selective catalysts for propylene in methanol-to-olefin process. Catalysts 2019, 9, 364. [CrossRef]

5. Luo, Y.; Miao, C.; Yue, Y.; Yang, W.; Hua, W.; Gao, Z. Chromium oxide supported on silialite-1 zeolite as a novel efficient catalyst for dehydrogenation of isobutene assisted by $\mathrm{CO}_{2}$. Catalysts 2019, 9, 1040. [CrossRef]

6. Saeid, S.; Kråkström, M.; Tolvanen, P.; Kumar, N.; Eränen, K.; Mikkola, J.; Kronberg, L.; Eklund, P.; Peurla, M.; Aho, A.; et al. Advanced oxidation process for degradation of carbamazepine from aqueous solution: Influence of metal modified microporous, mesoporous catalysts on the ozonation process. Catalysts 2020, 10, 90. [CrossRef]

7. Jeong, S.; Jeon, K.; Park, Y.; Kim, B.; Chung, K.; Jung, S. Catalytic properties of microporous zeolite catalysts in synthesis of isosorbide from sorbitol by dehydration. Catalysts 2020, 10, 148. [CrossRef]

8. Saeid, S.; Kråkström, M.; Tolvanen, P.; Kumar, N.; Eränen, K.; Mikkola, J.-P.; Kronberg, L.; Eklund, P.; Aho, A.; Palonen, H.; et al. $\mathrm{Pt}$ modified heterogeneous catalysts combined with ozonation for the removal of diclofenac from aqueous solutions and the fate of by-products. Catalysts 2020, 10, 322. [CrossRef]

9. Saeid, S.; Kråkström, M.; Tolvanen, P.; Kumar, N.; Eränen, K.; Peurla, M.; Mikkola, J.-P.; Mael, L.; Kronberg, L.; Eklund, P.; et al. Synthesis and characterization of metal modified catalysts for decomposition of ibuprofen from aqueous solutions. Catalysts 2020, 10, 786. [CrossRef]

10. Niu, X.; Wang, K.; Bai, Y.; Du, Y.E.; Dong, M.; Fan, W. Selective formation of para-xylene by methanol aromatization over phosphrous modified ZSM-5 zeolites. Catalysts 2020, 10, 484. [CrossRef]

11. Nishitoba, T.; Nozaki, T.; Park, S.; Wang, Y.; Kondo, J.N.; Gies, H.; Yokoi, T. CHA-type zeolite prepared by interzeolite conversion method using FAU and LTL-type zeolite: Effect of the raw materials on crystallization mechanism and physicochemical and catalytic properties. Catalysts 2020, 10, 1204. [CrossRef]

12. Vrbkova, E.; Vyskocilova, E.; Lhotka, M. Libor Cerveny, Solvent influence on selectivity in pinene oxide isomerization using $\mathrm{MoO}_{3}$-modified zeolite Beta. Catalysts 2020, 10, 1244. [CrossRef] 